Western Washington University

Western CEDAR

7-10-1986

\title{
Paleomagnetism of Middle Tertiary Volcanic- Rocks from the Western Cascade Series, Northern California
}

\author{
Myrl E. BeckJr. \\ Western Washington University, myrl.beck@wwu.edu \\ Russ R. Burmester \\ Western Washington University, russ.burmester@wwu.edu \\ Douglas E. Craig \\ C. Sherman Gromme \\ Ray E. Wells
}

Follow this and additional works at: https://cedar.wwu.edu/geology_facpubs

Part of the Geology Commons

\section{Recommended Citation}

Beck Jr., Myrl E.; Burmester, Russ R.; Craig, Douglas E.; Gromme, C. Sherman; and Wells, Ray E., "Paleomagnetism of Middle Tertiary Volcanic-Rocks from the Western Cascade Series, Northern California" (1986). Geology Faculty Publications. 25.

https://cedar.wwu.edu/geology_facpubs/25

This Article is brought to you for free and open access by the Geology at Western CEDAR. It has been accepted for inclusion in Geology Faculty Publications by an authorized administrator of Western CEDAR. For more information, please contact westerncedar@wwu.edu. 


\title{
PALEOMAGNETISM OF MIDDLE TERTIARY VOLCANIC ROCKS FROM THE WESTERN CASCADE SERIES, NORTHERN CALIFORNIA
}

\author{
Myr1 E. Beck, Jr.1, Russel1 F. Burmester ${ }^{1}$, and Douglas E. Craig ${ }^{2}$ \\ Department of Geology, Western Washington University, Bellingham \\ C. Sherman Gromme' and Ray E. Wells
}

U.S. Geological Survey, Menlo Park, California

\begin{abstract}
The Western Cascade Series (WCS) is a $3.5-\mathrm{km}-\mathrm{thick}$, crudely homoclinal (east dipping) calcalkaline volcanic sequence of mid-0ligocene to early Miocene age that crops out near the southern tip of the Cascade Range in northern California. The mean direction of remanent magnetization in the WCS is D, $4.9^{\circ} ; \mathrm{I}, 57.6^{\circ}$ (N, $\left.53 ; \mathrm{k}, 14.4 ; \alpha 95,5.3^{\circ}\right)$. When compared to a reference direction for the North American craton, the WCS direction indicates that the southern Cascade Range has rotated $14.0^{\circ} \pm 9.0^{\circ}$ since the WCS accumulated. A difference in mean direction between the lower and upper halves of the wCS suggests that much of this rotation occurred during the late oligocene. Six other paleomagnetic studies of rock units of an age roughly comparable to the WCS also are available from western Oregon, northwestern California, and southwestern Washington. All show statistically significant clockwise rotation (inclinations of all but one are concordant). Comparison of directions indicates that the Pacific Northwest did not rotate as a rigid body, but neither did it behave as a collection of small, independently rotating domains. The amount of rotation found throughout the area increases to the west or northwest, suggesting a driving force for rotation operating at the continental margin.
\end{abstract}

\section{Introduction}

Tertiary tectonic rotation in the Coast Range and Cascades of Washington and Oregon is well established; Magill et al. [1981] summarize work through 1980, and later contributions include Bates et al. [1981], Beck and Engebretson [1982], Beck et al. [1982] Magil1 et al. [1982], Mankinen and Irwin [1982], Sheriff [1984], and Wells and Coe [1985]. Important problems still remain to be solved, however, including the exact timing of rotation, the size of individual coherent rotated blocks, and the mechanism or mechanisms by which rotation occurred. This study of middle Tertiary volcanic rocks at the southern tip of the Cascade Range addresses some of these problems.

\footnotetext{
${ }^{1}$ Also at U. S. Geological Survey, Bellingham, Washington.

${ }^{2}$ Now at Alaska Exploration Group, Mobil oil Company, Dallas, Texas.
}

Copyright 1986 by the American Geophysical Union

Paper number 5B5758.

0148-0227/86/005B-5758\$05.00

\section{Geology}

The unit investigated is the Western Cascade Series (WCS) of Williams [1949], exposed along the Klamath River in northern California; the geography and simplified geology of the area are shown in Figure 1. As described by Williams, the WCS near the Klamath River consists of at least $3650 \mathrm{~m}$ of interbedded hypersthene-augite andesite flows and chemically similar pyroclastic rocks. A few scattered lenses of tuffaceous sedimentary rock also are present, and the series is intruded in places by small bodies of rhyolite, andesite, and basalt. Williams stated that the average WCS flow is 3-10 m thick, although flows as thick as $30 \mathrm{~m}$ are encountered. Judging from the detailed stratigraphic sequence for the upper part of the WCS published by Hammond [1983], roughly half of the series consists of lava flows. Thus we estimate that approximately 150-200 separate lava flows are contained within the wCS section along the Klamath River, of which we have sampled about a third.

Williams [1949] dated the Western Cascade Series as late Eocene or Oligocene to late Miocene, largely on the basis of plant fossils identified by $R$. W. Chaney (unpublished data, 1949). Fission track ages by J. A. Vance (unpublished data, 1982) date the bottom of the sequence along the Klamath River at slightly more than $33 \mathrm{~m} . \mathrm{y}$. (roughly middle oligocene).

Hammond [1983] reports a K/Ar age of $23.2 \pm 0.8$ m.y. from a flow slightly above the middle of the sequence. Thus the section we sampled spans at least $10 \mathrm{~m} . \mathrm{y}$. (mid-01igocene to early Miocene). According to Ness et al. [1980] there were at least 28 polarity transitions in the interval 33$23 \mathrm{Ma}$. Our results suggest that we have detected 17.

The structure of the Western Cascade Series along the Klamath River is roughly homoclinal, with gentle $\left(0-20^{\circ}\right)$ dips, mostly to the northeast and east-northeast. No major faults are known to duplicate the section [Williams, 1949; Hammond, 1983 ; J.A. Vance personal communication, 1981]. Williams [1949] believed that the WCS volcanic rocks were erupted from volcanos or fissures located "far to the east." This, plus the great thickness of the sequence, argues that the northeasterly dips observed in the field are mostly tectonic (acquired by tilting after the rocks were deposited) and not original (acquired, for instance, by deposition on the flanks of a volcano).

The Western Cascade Series unconformably overlies the Upper Cretaceous Hornbrook Forma- 


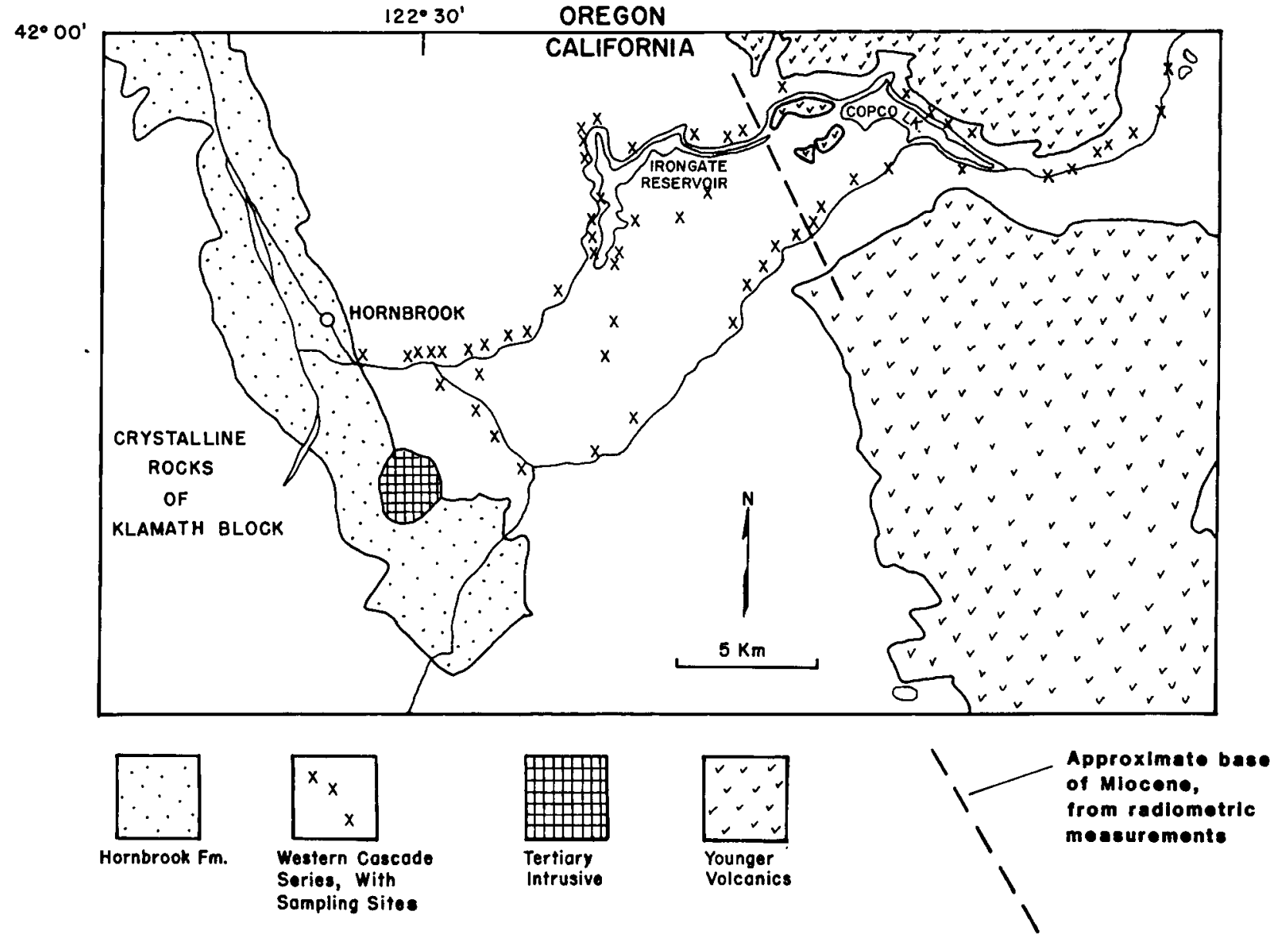

Fig. 1. Location map, modified from Craig [1981], showing sampling sites.

tion. The Hornbrook Formation is a shallow marine sequence that overlaps Paleozoic to midMesozoic crystalline rocks of the Klamath Mountains farther west. Overlying the WCS are volcanic rocks of the High Cascade Group, largely Pliocene and younger in age.

\section{Previous Paleomagnetic Investigations}

The paleomagnetism of the Western Cascade Series was first studied by Beck [1962], who obtained directions of magnetization for 23 lava flows, mostly from the lower part of the section. The mean direction for the study was declination (D), $13^{\circ}$; inclination (I), $65^{\circ}$; circle of $95 \%$ confidence $\left(\alpha_{95}\right), 6.2^{\circ}$. This mean direction lies about $18^{\circ}$ clockwise of the expected North American direction for $30 \mathrm{Ma}$ Craig [1981] tried to define this apparent rotation more precisely. His results, based on 44 sampling sites, shows $12^{\circ}$ of clockwise rotation. Craig et al. [1981], reporting on a slightly larger data set, still found a rotation of $12^{\circ}$ but noted that it mainly involved rocks from the lower part of the section. They concluded that rotation of the southern Cascades was nearly complete by the beginning of Miocene tîme.

\section{Experimental Procedures}

We sampled along three major roads that traverse the Western Cascade Series near the
Oregon-California border (Figure 1): sites are located by latitude and longitude in Table 1 . Most sites were artificial exposures (road cuts or quarries). We collected 4-12 samples at each site by drilling and orienting in situ. Cores were oriented by magnetic compass, checked in most cases by sun compass or the back-azimuth technique. Structural attitudes were recorded at or near each site.

In the laboratory the oriented cores were cut into standard paleomagnetic specimens, and their natural remanent magnetizations (NRM) measured. All samples were alternating field (af) demagnetized, using a two-axis reciprocating tumbler. Peak fields used in the demagnetization experiments ranged up to $100 \mathrm{mT}$. From each site we selected two or more pilot samples for progressive af demagnetization, and from these we selected one or more "optimum" levels of af demagnetization for the rest of the site. Where more than one optimum level was used, the characteristic direction for the site was chosen as the level that yielded minimum dispersion. Examples of the response of these rocks to af demagnetization are given in Figure 2.

\section{Paleomagnetic Results}

Table 1 summarizes paleomagnetic results for the Western Cascade Series, and Table 2 gives mean directions, to be discussed later. In Table 1 the sites are listed in what we believe to be correct stratigraphic order, from 1 at the bottom 
of the section to 60 at the top. However, to order the sites in this fashion entailed projecting attitudes over distances of up to several miles, so some errors in stratigraphic positioning are likely. Directions listed in Table 1 have been corrected for tilt; the dips and strikes used in these calculations also are given in Table 1. We have not listed site-mean virtual geomagnetic poles (VGP) in Table 1, but we have tabulated the geographic coordinates for each site. This will enable the reader to calculate site-mean VGP.

Table 2 contains various mean directions derived from the data of Table 1 . In making these calculations, we have eliminated nine sites (indicated by numbers in the first column of Table 1), and we have split two sites ( 34 and 37 ) into independent subsites. In accordance with longstanding practice, we have discarded sites for which the mean direction is poorly determined: $\alpha_{95}>15^{\circ}$ was used as a cutoff. We have also eliminated "transitiona1" sites. For the purposes of this study a transitional site is one whose VGP falls more than $45^{\circ}$ from both the mean normal and the mean reverse VGP for the entire data set and which has sites of opposite polarity (or other transitional sites) above and below it. Sites labeled transitional $(\mathrm{T}$ ) in Table 1 may not all represent material that was magnetized during a polarity transition (sites 55-57 almost certainly do), but they are unlikely to be legitimate samples of a dipole field direction, and so we discard them. Finally, in two instances (sites 34 and 37 ), exposures sampled as a single flow were shown in the laboratory to contain two distinct, we11-grouped directions. In both cases the sampling areas for the distinct groups were separated from one another by several meters of no exposure. Apparently, at these two sites we missed flow contacts (and in the case of site 37 a polarity transition as well). Accordingly, each subset was elevated to site status. This gave 53 acceptable sites for the calculations of Table 2. Of all 62 sites, 36 have normal polarity, 21 are reverse, and 5 are transitional.

The first two entries in Table 2 consist of means for the entire data set. Calculation 1 is the vector sum of 53 site-mean directions, with each site-mean direction assigned unit weight (such calculations will hereafter be termed "Fisher means" after Fisher [1953], who first suggested the method). Calculation 2 also is a Fisher mean for the entire data set, but in this case the calculation was performed using site VGPs. The two methods give results that are nearly, but not precisely, identical: differences amount to about $2.5^{\circ}$.

Magi11 and Cox [1980] and Magi11 et al.[1981] have proposed that rotation in western Oregon occurred in two episodes (post-20 Ma; pre-45 Ma) separated by a 25-m.y. hiatus that included all of the 0ligocene. Because our data set spans much of the Oligocene, we can test for 0ligocene rotation by comparing directions within the upper and lower portions of the section. The Magill chronology predicts that the two directions will be identical (assuming little or no polar wander). Entries 3-6, Table 2, are data for this test. We separated Table 1 into two subsets, a lower (older) set (sites 1-30) and an upper set (sites 31-60). Both subsets span many hundreds of meters of section and include several polarity transitions, so there is little doubt that both average secular variation adequately. Calculations 3 and 4, Table 2, are Fisher means for site-mean directions for the upper and lower subsets, respectively. Similarly, entries 5 and 6 are Fisher means of site VGP for the upper and lower subsets. The significance of these calculations is discussed below.

Table 2 also contains Fisher means for sitemean directions subdivided by polarity. A comparison of normal and reverse subsets sometimes is useful as evidence of inadquate magnetic cleaning; if the subsets are not antiparallel, an unremoved secondary magnetization may be present. For the Western Cascade Series the $N$ and $R$ directions are 174.60 apart, tending to confirm that the directions are primary.

Calculation 7, Table 2, is a Fisher mean of all acceptable, in situ directions. That is, data for this calculation consist of site-mean directions uncorrected for dip. This calculation is used in a modified fold test and in a discussion of the question of original versus tectonic dip, given below.

The final entry in Table 2 gives the reference pole and expected direction with which the Western Cascade Series measurements are to be compared. We use the 22-38 Ma pole of Dieh1 et al. [1983], which is a Fisher mean of 102 VGP from the North American craton. Many other reference poles are available, but they do not differ significantly for this time period.

\section{Interpretation of Paleomagnetic Data}

We next compare the various directions calculated for the Western Cascade Series with the reference direction and pole (entry X, Table 2 ) and with one another. These comparisons usually hinge on statistical arguments [e.g., Beck, 1980; Demarest; 1983; McWilliams, 1984]. Table 3 summarizes the relevant calculations. In this section we will explain and evaluate the entries in Table 3 . Their tectonic significance is discussed later.

Calculation $I$, Table 3 , gives rotation $(R)$ and flattening (IF) figures for the Western Cascade Series, calculated using equations given by Beck [1980], with confidence limits modified after Demarest [1983]: Like nearly every volcanic unit studied so far in the Washingtonoregon Cascades and Coast Range, WCS rocks from northern California show a statistically significant clockwise rotation, accompanied by a smail flattening of inclination that is not significant at the $95 \%$ confidence level. In this calculation (I) the expected direction, derived from the Diehl et al. [1983] reference pole, is compared directly with the observed WCS mean direction (calculation 1, Table 2). Most estimates of rotation (R) and flattening (IF) have been made in this way.

In calculation II, Table $3, R$ and IF and their respective confidence limits are calculated in another way, using poles. 'This method is useful, for instance, in analyzing published paleomagnetic data for which only a mean pole is available. As can be seen by comparing entries $I$ and II, Table 3, the two methods give very similar results. $R$ and IF may be calculated from poles using the following expressions: 
TABLE 1. Paleomagnetic Results for Western Cascade Series, Northern California

\begin{tabular}{|c|c|c|c|c|c|c|c|c|c|c|c|}
\hline No. & $\mathbf{N}$ & Po 1 & D & I & k & $\alpha_{95}$ & $\lambda$ & $\phi$ & Str & Dip & Notes \\
\hline 60 & 7 & $\mathbf{R}$ & 35.5 & 54.0 & 99 & 6.1 & 42.00 & 122.18 & 305 & 13 & \\
\hline 59 & 7 & $\mathbf{R}$ & 2.0 & 37.0 & 106 & 5.9 & 41.98 & 122.18 & 312 & 15 & \\
\hline 58 & 8 & $\mathbf{R}$ & 41.5 & 61.0 & 59 & 6.5 & 41.97 & 122.20 & 315 & 8 & \\
\hline 57 & 5 & $\mathrm{~T}$ & 39.4 & -28.1 & 13 & 21.6 & 41.95 & 122.22 & 335 & 8 & 1,2 \\
\hline 56 & 9 & $\mathrm{~T}$ & 46.5 & -9.5 & 104 & 5.1 & 41.96 & 122.23 & 315 & 10 & 2 \\
\hline 55 & 7 & $T$ & 150.5 & 12.5 & 8 & 45.7 & 41.96 & 122.25 & 335 & 8 & 1,2 \\
\hline 54 & 7 & $\mathrm{~N}$ & 323.5 & 79.5 & 160 & 4.2 & 41.97 & 122.28 & 325 & 15 & \\
\hline 53 & 7 & N & 35.5 & 40.5 & 6 & 27.6 & 41.98 & 122.28 & 325 & 15 & 1 \\
\hline 52 & 8 & $\mathbf{N}$ & 326.5 & 78.5 & 700 & 2.1 & 41.98 & 122.29 & 325 & 15 & \\
\hline 51 & 6 & $\mathbf{N}$ & 344.0 & 63.0 & 23 & 11.8 & 41.98 & 122.32 & 325 & 15 & \\
\hline 50 & 7 & $\mathbf{N}$ & 21.5 & 64.5 & 117 & 4.9 & 41.95 & 122.30 & 325 & 10 & \\
\hline 49 & 7 & $\mathbf{N}$ & 300.5 & 62.0 & 6 & 16.8 & 41.96 & 122.31 & 270 & 15 & 1 \\
\hline 48 & 5 & $\mathbf{N}$ & 5.5 & 45.0 & 59 & 10.0 & 41.99 & 122.35 & 320 & 15 & \\
\hline 47 & 7 & $\mathrm{~N}$ & 326.0 & 68.0 & 310 & 3.0 & 41.95 & 122.33 & 270 & 15 & \\
\hline 46 & 7 & $\mathbf{R}$ & 322.0 & 71.0 & 145 & 4.4 & 41.93 & 122.35 & 315 & 20 & \\
\hline 45 & 5 & $\mathbf{R}$ & 329.0 & 55.5 & 592 & 2.6 & 41.93 & 122.35 & 350 & 15 & \\
\hline 44 & 7 & $\mathbf{R}$ & 1.0 & 47.0 & 187 & 3.8 & 41.97 & 122.35 & 315 & 17 & \\
\hline 43 & 7 & $\mathbf{R}$ & 42.5 & 44.5 & 157 & 4.2 & 41.97 & 122.38 & 335 & 10 & \\
\hline 42 & 7 & $\mathbf{R}$ & 31.0 & 49.5 & 303 & 3.0 & 41.97 & 122.38 & 335 & 10 & \\
\hline 41 & 7 & $\mathbf{R}$ & 314.5 & 76.5 & 28 & 9.9 & 41.93 & 122.35 & 350 & 15 & \\
\hline 40 & 6 & $\mathbf{N}$ & 24.0 & 57.0 & 47 & 8.3 & 41.92 & 122.37 & 350 & 15 & \\
\hline 39 & 7 & $\mathrm{~N}$ & 311.5 & 67.5 & 65 & 6.6 & 41.97 & 122.40 & 335 & 5 & \\
\hline 38 & 7 & $\mathbf{R}$ & 344.5 & 87.0 & 176 & 4.0 & 41.92 & 122.37 & 320 & 10 & \\
\hline $37 \mathrm{E}$ & 3 & $\mathbf{R}$ & 330.5 & 56.5 & 173 & 9.4 & 41.95 & 122.38 & 320 & 10 & \\
\hline $37 \mathrm{~W}$ & 4 & $\mathrm{~N}$ & 23.5 & 54.5 & 38 & 11.4 & 41.95 & 122.38 & 320 & 10 & \\
\hline 36 & 7 & $\mathbf{N}$ & 5.5 & 62.5 & 324 & 2.9 & 41.90 & 122.38 & 320 & 10 & \\
\hline 35 & 7 & $\mathrm{~N}$ & 359.5 & 33.5 & 228 & 3.5 & 41.93 & 122.40 & 320 & 10 & \\
\hline $34 \mathrm{E}$ & 4 & $\mathrm{~N}$ & 355.5 & 65.0 & 49 & 10.0 & 41.97 & 122.42 & 315 & 5 & \\
\hline $34 \mathrm{~W}$ & 3 & $\mathbf{N}$ & 300.0 & 37.0 & 108 & 11.9 & 41.97 & 122.42 & 315 & 5 & \\
\hline 33 & 7 & $\mathrm{~N}$ & 0.0 & 50.0 & 204 & 4.0 & 41.90 & 122.38 & 320 & 10 & \\
\hline 32 & 7 & $\mathbf{N}$ & 344.5 & 58.5 & 75 & 7.0 & 41.97 & 122.43 & 300 & 5 & \\
\hline 31 & 6 & $T$ & 252.5 & 51.0 & 1910 & 1.5 & 41.97 & 122.43 & 120 & 20 & 2 \\
\hline 30 & 9 & $\mathbf{R}$ & 350.0 & 39.5 & 124 & 4.4 & 41.93 & 122.42 & 310 & 5 & \\
\hline 29 & 7 & $\mathbf{N}$ & 296.0 & 63.0 & 41 & 9.6 & 41.97 & 122.43 & 120 & 20 & \\
\hline 28 & 6 & $\mathbf{N}$ & 50.5 & 77.5 & 27 & 13.3 & 41.97 & 122.43 & 110 & 22 & \\
\hline 27 & 7 & $\mathbf{R}$ & 296.0 & 76.0 & 46 & 9.0 & 41.95 & 122.43 & 170 & 7 & \\
\hline 26 & 7 & $\mathrm{~N}$ & 314.0 & 57.5 & 120 & 5.5 & 41.96 & 122.43 & 195 & 23 & \\
\hline 25 & 4 & $\mathbf{N}$ & 31.5 & 45.0 & 33 & 12.3 & 41.95 & 122.43 & 345 & 20 & \\
\hline 24 & 7 & $\mathrm{~N}$ & 353.0 & 52.5 & 51 & 7.5 & 41.93 & 122.43 & 285 & 17 & \\
\hline 23 & 7 & $\mathbf{R}$ & 32.0 & 35.0 & 840 & 1.8 & 41.92 & 122.43 & 345 & 20 & \\
\hline 22 & 7 & $\mathrm{~N}$ & 40.5 & 53.0 & 161 & 4.2 & 41.92 & 122.43 & 310 & 22 & \\
\hline 21 & 8 & $\mathrm{~N}$ & 38.0 & 42.5 & 167 & 3.8 & 41.92 & 122.43 & 310 & 22 & \\
\hline 20 & 7 & $\mathrm{~N}$ & 47.0 & 35.5 & 374 & 2.7 & 41.92 & 122.43 & 340 & 15 & \\
\hline 19 & 4 & $\mathrm{~N}$ & 11.0 & 64.5 & 140 & 5.9 & 41.90 & 122.42 & 320 & 10 & \\
\hline 18 & 7 & $\mathrm{~N}$ & 27.0 & 48.5 & 192 & 3.8 & 41.85 & 122.42 & 340 & 19 & \\
\hline 17 & 6 & $\mathbf{R}$ & 34.0 & 69.0 & 323 & 3.2 & 41.90 & 122.45 & 320 & 10 & \\
\hline 16 & 7 & $\mathbf{R}$ & 19.0 & 19.5 & 77 & 6.9 & 41.87 & 122.42 & 340 & 19 & \\
\hline 15 & 7 & $\mathbf{R}$ & 337.0 & 28.0 & 88 & 6.7 & 41.88 & 122.45 & 320 & 10 & \\
\hline 14 & 7 & $\mathbf{R}$ & 13.5 & 52.5 & 100 & 6.1 & 41.85 & 122.43 & 340 & 19 & \\
\hline 13 & 6 & $\mathbf{R}$ & 348.0 & 50.0 & 116 & 5.3 & 41.88 & 122.47 & 320 & 10 & \\
\hline 12 & 5 & $\mathbf{N}$ & 359.5 & 56.0 & 59 & 10.0 & 41.88 & 122.47 & 320 & 5 & \\
\hline 11 & 5 & $\mathbf{N}$ & 15.0 & 41.5 & 16 & 19.9 & 41.88 & 122.46 & 330 & 15 & 1 \\
\hline 10 & 10 & $\mathbf{N}$ & 19.0 & 51.0 & 10 & 14.9 & 41.87 & 122.48 & 330 & 18 & \\
\hline 9 & 6 & $\mathrm{R}$ & 18.0 & 21.5 & 98 & 6.8 & 41.88 & 122.49 & 258 & 9 & \\
\hline 8 & 7 & $\mathbf{N}$ & 10.0 & 53.0 & 181 & 3.9 & 41.85 & 122.47 & 330 & 18 & \\
\hline 7 & 7 & $\mathbf{N}$ & 6.0 & 40.5 & 258 & 3.3 & 41.85 & 122.47 & 335 & 18 & \\
\hline 6 & 7 & $\mathrm{~N}$ & 358.5 & 58.5 & 828 & 1.8 & 41.88 & 122.48 & 330 & 15 & \\
\hline 5 & 7 & $\mathbf{N}$ & 15.5 & 52.5 & 218 & 3.6 & 41.88 & 122.48 & 320 & 15 & \\
\hline 4 & 7 & $\mathbf{N}$ & 20.0 & 30.0 & 12 & 22.7 & 41.88 & 122.50 & 320 & 15 & 1 \\
\hline 3 & 7 & $\mathrm{~T}$ & 156.0 & 79.5 & 26 & 12.0 & 41.87 & 122.50 & 330 & 15 & 2 \\
\hline 2 & 9 & $\mathbf{R}$ & 347.5 & 50.5 & 69 & 5.6 & 41.88 & 122.52 & 295 & 13 & \\
\hline 1 & 4 & $\mathbf{N}$ & 35.0 & 61.0 & 97 & 7.1 & 41.88 & 122.53 & 345 & 10 & \\
\hline
\end{tabular}

No., arbitrary flow number, from 1 at bottom to 60 at top; $N$, number of samples; Pol, geomagnetic polarity (N, normal; $R$, reverse; $T$, probably 


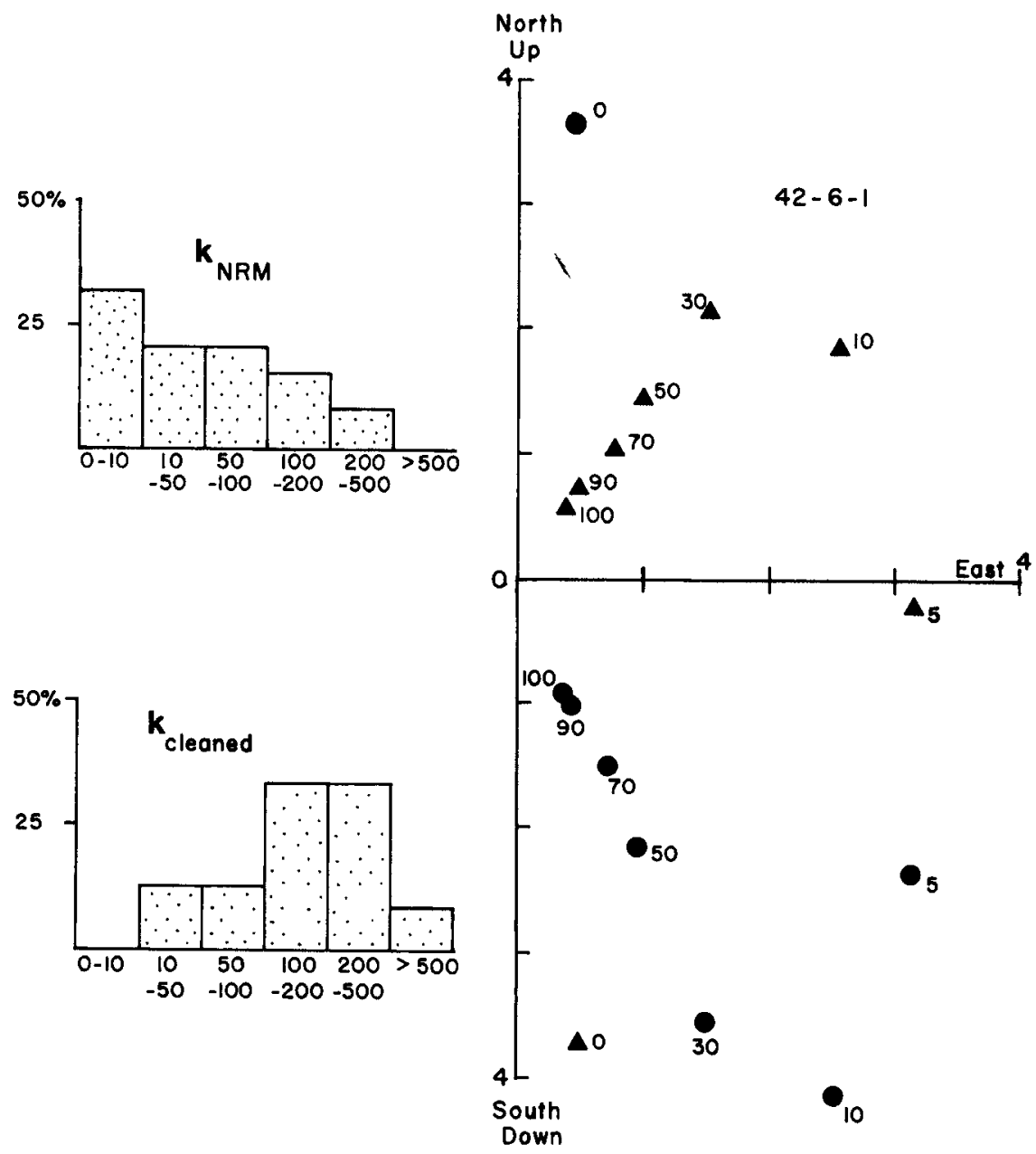

Fig 2. Effect of af demagnetization on volcanic rocks of the Western Cascade Series. Left side shows improvement in estimate of Fisher's [1953] precision parameter $k$, for the entire data set. Right side is a typical orthogonal plot, showing change in direction and intensity. Triangles (circles) show vertical (horizontal) component in milliteslas. No tectonic correction has been made. The sample selected shows below average magnetic stability for these rocks.

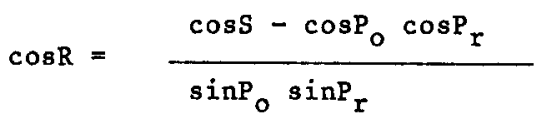

$\Delta R=0.8\left(\Delta D^{2}{ }_{0}+\Delta D^{2}{ }_{r}\right)^{1 / 2}$

$\sin \Delta D_{0}=\frac{\sin A_{0}}{\sin P_{0}}$

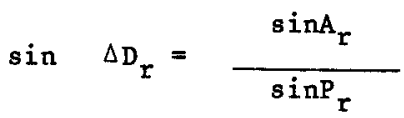

$$
\begin{aligned}
& I F=I_{r}-I_{0} \\
& \Delta I F=0.8\left(\Delta I_{r}^{2}+\Delta I_{0}^{2}\right) 1 / 2 \\
& \Delta I_{r}=\frac{2 A_{r}}{1+3 \cos ^{2} P_{r}} \\
& \Delta I_{0}=\frac{2 A_{0}}{1+3 \cos ^{2} P_{0}}
\end{aligned}
$$

In these equations, $R$ and $I F$ represent rotation

transitional); D,I, declination, inclination (reverse directions inverted); $k$, best estimate of Fisher's [1953] precision paramater; $\alpha$, radius of circle of 95\% confidence about the mean direction, assuming a Fisher [1953]

distribution; $\lambda$, $\phi$, north latitude and west longitude of sampling site; str, Dip, strike and dip of bed -- direction of dip is 90 clockwise from strike. Notes: 1, site eliminated because $\alpha_{95}>15 ; 2$, site eliminated because direction appears to be transitional. For definition of "transitional," see text. Directions corrected for tilt of beds. 
TABLE 2. Mean and Expected Directions and Poles, Western Cascade Seriesv

\begin{tabular}{lrlrrrrrrr}
\hline Calc & N & D & I & $k$ & $\alpha_{95}$ & $\lambda^{\prime}$ & $\phi^{\prime}$ & $K$ & $A_{95}$ \\
\hline 1 & 53 & $4.9^{\circ}$ & $57.6^{\circ}$ & 14.4 & $5.3^{\circ}$ & & & & \\
2 & 53 & & & & & $86.9^{\circ} \mathrm{N}$ & $347.1^{\circ} \mathrm{E}$ & 9.0 & $6.9^{\circ}$ \\
3 & 26 & 357.9 & 61.8 & 16.5 & 7.2 & & & & \\
4 & 27 & 10.3 & 53.2 & 13.9 & 7.7 & & & & \\
5 & 26 & & & & & 85.8 & 205.9 & 9.3 & 9.8 \\
6 & 27 & & & & & 80.5 & 2.6 & 9.5 & 9.5 \\
$\mathrm{~N}$ & 32 & 4.8 & 59.6 & 17.1 & 6.3 & & & & \\
$\mathrm{R}$ & 21 & 185.1 & -54.0 & 11.4 & 9.7 & & & & \\
7 & 53 & 350.1 & 63.6 & 17.2 & 4.9 & & & & \\
$\mathrm{X}$ & 102 & 350.9 & 60.6 & & & 83.2 & 148.0 & 12.8 & 4.1 \\
\hline
\end{tabular}

Calc, number of calculation, discussed in text and summarized below. $N$, number of sites used in calculation; D,I, declination, inclination; $k$, best estimate of Fisher [1953] precision parameter, field directions; $\alpha_{95}$, radius of circle of $95 \%$ confidence about mean direction; $\lambda^{\prime}, \phi^{\prime}$, latitude and longitude of pole; $\mathrm{K}$, best estimate of Fisher [1953] precision parameter, mean pole; $A_{95}$, circle of $95 \%$ confidence about mean pole. Explanation of various calculations: 1 , all acceptable sites, using site-mean directions; 2 , all acceptable sites, using VGP; 3 , upper half of section using directions; 4, lower half, directions; 5 , upper half, VGP; 6 , lower half, VGP; $N$, all normal polarity directions; $R$, all reverse polarity directions; 7 , In situ directions, entire data set; $X$, expected direction and pole, from Diehl et al. [1983].

and flattening, with their respective confidence limits, $R$ and IF. The confidence level of $R$ and IF is selected by the investigator; $95 \%$ is the usual choice. In ( 1 ), $S$ is the angular distance between observed pole and reference pole, $P_{0}$ is the angular distance between the observed pole and the sampling site (observed colatitude), and $P_{F}$ is the angular distance from sampling site to reference pole (the expected colatitude). $\Delta R$ and $\Delta I F$ are calculated using confidence limits on declination $\left(\Delta D_{0}\right.$ and $\left.\Delta D_{r}\right)$ and inclination $\left(\Delta I_{0}\right.$ and $\left.\Delta I_{r}\right)$, respectively. These in turn are functions of the radius of the circle of confidence about the appropriate mean poles ( $A_{0}$ and $A_{r}$, usually calculated at the $95 \%$ level), and colatitude. The factor 0.8 in (2) and (6) follows Demarest 1983 ; a similar factor should be inserted into (3) and (4) of Beck

1980 . (Note that a measure of north-south displacement more directly useful than the commonly used flattening (IF) is simply $P=P_{-}$ $P$, the poleward displacement. The confidenct limit on $P$ is $\triangle P=0.8\left(A^{2}{ }^{\prime}+A^{2}\right)^{1 / 2}$.

The subsets of Table 1 (upper and lower WCS) remain to be tested. From a superficial examination of entries 3 and 4, Table 2, it appears that the lower half of the Western Cascade Series shows much more rotation than the upper half. This might be taken to indicate that rotation was going on during the 0ligocene, while the WCS accumulated. The mean inclination of the lower flows also is somewhat flatter than that of the upper half of the section, which might indicate northward transport. However, it is equally possible that these differences have no tectonic significance whatsoever; they may, for instance, simply represent random differences between two independent estimates of the mean of a single population. Statistical tests are required.
The traditional way to test for independence of paleomagnetic data sets involves overlap or nonoverlap of confidence circles, almost invariably calculated at the $95 \%$ level. If the circles do not overlap, the sets are judged to be independent. By this test the upper and lower halves of the Western Cascade Series do not have independent directions. This is true whether directions (calculations 3 and 4, Table 2), or mean VGP (calculations 5 and 6 , Table 2), are used in the analysis. For instance, mean directions 3 and 4 , Table 2, are $10.8^{\circ}$ apart. The sum of their $95 \%$ confidence limits, however, is $14.9^{\circ}$, giving an overlap of $4.1^{\circ}$. Similarly, confidence circles about mean poles 5 and 6 , Table 2 , overlap by $5.8^{\circ}$.

A more sensitive test for independence is the F ratio test, recently discussed by McWilliams [1984]. Here again the level of significance can be chosen by the investigator, but $95 \%$ is used in most instances. Applying the F test (at the 95\% confidence level) to the Western Cascade Series data gives mixed results. For 2 and 51 degrees of freedom the critical value of $F$ is 3.14. The appropriate $F$ ratio for directions is 3.34 , and for VGP it is 3.08 . Thus, at $95 \%$ confidence the $F$ test indicates that the two subsets of directions are independent but the subsets of VGP are not. Both would be judged significantly different at the $90 \%$ confidence level.

Most paleomagnetists have programmed into their computers or hand calculators the capacity to calculate confidence circles at any confidence level whatever. Few take advantage of that capacity, however; the $95 \%$ confidence level is used almost exclusively. However, other "levels" may be just as useful. It is an easy matter, given two paleomagnetic data sets with different means, to vary the confidence level in an effort 
TABLE 3. Rotations, Flattenings, in Western Cascade Series, From the Data in Table 2

\begin{tabular}{lrlr} 
Calc & $\mathrm{R} \pm \Delta \mathrm{R}$ & $\mathrm{IF} \pm \Delta \mathrm{IF}$ \\
\hline I & $14.0 \pm 9.0$ & $3.0 \pm 5.1$ \\
II & $13.0 \pm 8.6$ & $0.7 \pm 5.6$ \\
III & $7.0 \pm 13.0$ & $7.4 \pm 5.4$ \\
IV & $19.4 \pm 11.2$ & $-3.2 \pm \frac{ \pm}{ \pm}$ & 5.8 \\
V & $6.0 \pm 12.1$ & $5.1 \pm 8.0$
\end{tabular}

Rotations ( $R$ ) and flattenings (IF), with their respective $95 \%$ confidence limits. Calculations after Beck [1980], Demarest [1983] and equations (1) - (8) of this paper. Reference pole from Diehl et a1. [1983]. I, entire data set, using directions; II, entire data set, using VGP; III, upper half of data set, directions; IV, lower half, directions; $V$, upper half of data set, poles; VI, lower half, poles.

to find at what level they are "significantly" different; that is, to determine $P$ such that $A 1$ $+A 2=S$, where $S$ is the angle between the two means, $A 1$ and $A 2$ the radii of the two confidence circles, and $p$ the probability level. The geological interpretation (rotated, translated, or not?) is less straightforward and automatic when this technique is used, but it may ultimately be more useful. This method shows that directions in the upper and lower WCS subsets are significantly different at $80 \%$ probability and poles at $77.5 \%$. These seem like exce1lent odds to us, and so we conclude that the upper and lower wCS subsets have different paleomagnetic directions and that some rotation (and northward translation?) probably took place during the 0ligocene.

Calculations III and IV, Table 3 , give rotations and flattenings for the upper and lower Western Cascade Series directions, respectively; calculations V and VI give the same statistics, based on mean VGPs. It appears from these figures that about $12^{\circ}$ of clockwise rotation was acquired between the mean ages of the two data sets, that is, during the late Oligocene. It also appears that very little rotation has occurred since early Miocene time. The positive flattening shown by the older (calculation IV) data also is noteworthy.

\section{A Modified Fold Test and The Question of Original Dip}

It will not have escaped the reader that the $R$ and IF calculations discussed in the preceding section are for tilt-corrected results only and that nothing has been said about entry 7, Table 2 , the Fisher mean of in situ directions. The same reader will have noticed that this in situ mean direction is essentially identical to the expected direction $\left(R=-0.8 \pm 12.4^{\circ} ;\right.$ IF $=-3.0 \pm$ $6.0^{\circ}$ ) and that the process of "tilt-correcting" the wCS data produces an overall increase in scatter (the Fisher [1953] precision parameter drops from 17.2, uncorrected to 14.4 , corrected). This complicates our task of tectonic interpretation.
It has been recognized for some time that tilt corrections are a principal source of inaccuracy in paleomagnetic studies of volcanic rocks, especially volcanic rocks from calcalkaline arc sequences. The difficulties encountered are twofold: (1) measuring structural attitudes correctly, and (2) knowing whether or not to correct for them. Since not all volcanic sequences have sedimentary interbeds intercalated conveniently throughout, it often is necessary either to project such sedimentary (or pyroclastic) attitudes as do exist for great distances or to measure strike and dip on the flows themselves. Either procedure is subject to significant error. Also, even if an accurate strike and dip can be measured, it is not always obvious whether it is primary or tectonic, as anyone who has seen andesitic lava flows dipping at angles of up to $15^{\circ}$ on the side of a composite volcano will attest. Two tools are available to help solve the tilt correction dilemma: the fold test (or, where one is present, the conglomerate test) and common sense.

A modified fold test attempted for the Western Cascade Series was indeterminant. The geology of the wCS outcrop area does not permit a formal fold test, such as the one proposed by McFadden and Jones [1981], which requires rigid-body rotations that divide a data set into subsets, each of which retains the original dispersion. In the WCS example the sequence is grossly monoclinal, with measured strikes in the NW quadrant and shallow dips, mostly to the NE, but with a few to the SW. It is not clear to what extent these variations in attitude reflect small structures and to what extent they are simply error.

A version of the fold test suitable for terrains with complicated or poorly understood structure is simply to compare the dispersion of paleomagnetic directions before and after correction for tilt. If the magnetization is primary and acquired before tilting and if the attitudes are measured correctly, then dispersion ought to be less after correction. Conversely, if the magnetization was acquired after tilting (as in the case of secondary remagnetization) or if the dips are primary (the lava solidifed on the side of a hil1), then tilt correction will increase the dispersion. Cox [1969] provides a test for the statistical significance of changes in dispersion. In the case of the WCS, dispersion increases ( $k$ decreases) when the tilt corrections are applied, but the increase is not statistically significant (at $95 \%$ confidence).

Thus we are forced back upon geological comon sense. The question we need to consider is the following: Is it likely, given the geological setting of the Western Cascade Series, that the flows we sampled were magnetized in situ, that is, after their present structure was acquired? We think not, for reasons explained below.

Figure 3 shows the outcrop extent of the Cascade Range [after Hammond, 1979]. The oldest part of the Cascade volcanic suite, the lower Western Cascade Series [Hammond, 1979], crops out intermittently along the western edge of the range from north central California to the Oregon-Washington border (in Washington these older rocks form the bulk of the range). Nearly everywhere that lower WCS rocks are exposed, they are 


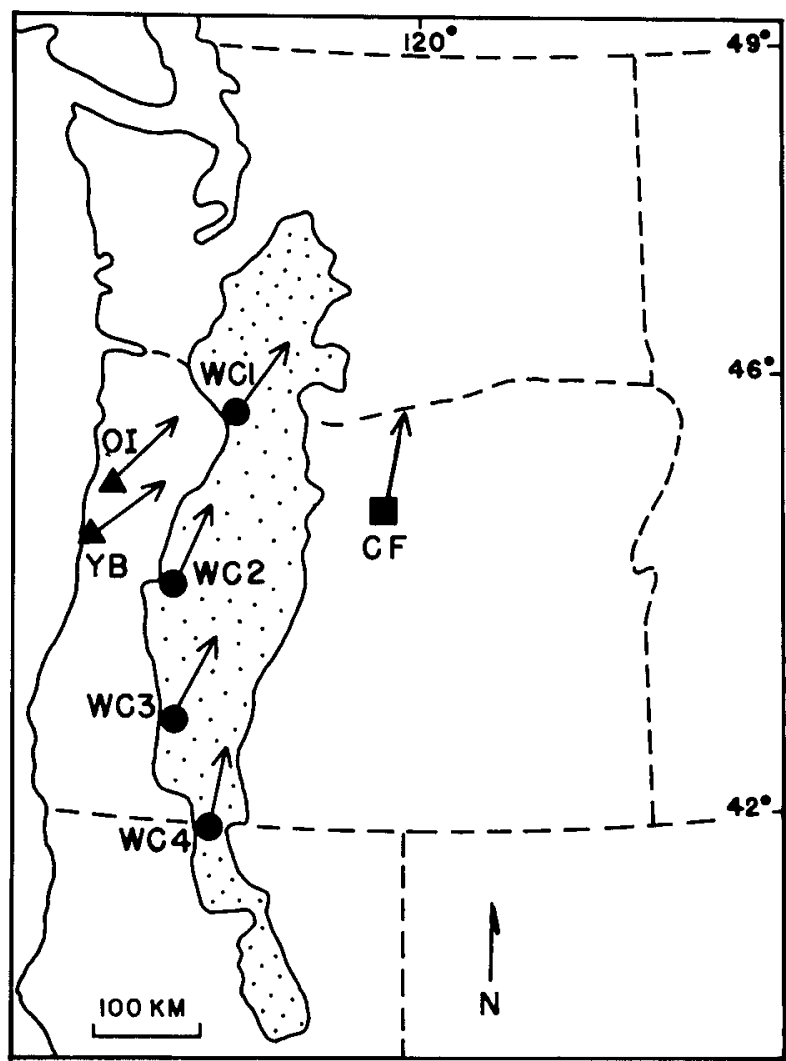

Fig. 3. "Mostly Oligocene" paleomagnetic studies for the Pacific Northwest. Arrow indicates rotation $\left(D_{0}-D_{x}\right)$, not observed declination. Thus a study for which $R=0$ would be shown by an arrow pointing due north. CF, Clarno Formation [Beck et al., 1978; C. S. Gromme et al., manuscript in preparation, 1986]; WCl, Ohanapecosh Formation [Bates et al., 1981]; WC2 and WC3, Western Cascades Series [Magil1 and Cox, 1980 ]; WC4, Western Cascade Series (this paper); OI, Oligocene intrusives, Oregon Coast Range [Beck and Plumley, 1980]; YB, Yachats basalts [Simpson and Cox, 1977]. Stippled pattern shows extent of Cascade volcanic rocks. Note that $C F$ may be more late Eocene than Oligocene in age.

flat-lying or dip gently eastward beneath the Quaternary volcanos that cap the range. In places the E-W linear extent of these gently dipping wCS sequences exceeds $50 \mathrm{~km}$. These observations argue that the WCS represents a horizontal stack of lavas that has been downwarped to the east by isostatic sinking of the crust under a load of Quaternary volcanos or perhaps upwarped to the west by uplift in the Coast Range and Klamath Mountains. Original dip is an unlikely alternative. Original dip to the east would require a linear source of calc-alkd line magma (of oligocene age) running nearly the entire length of the Coast Range in Oregon and Washington and also penetrating the Klamath Mountains in northern California. To the best of our knowledge, no such source exists.

If the Western Cascade Series dips are not original, the rocks might still have been magnetized in situ if the magnetizations are not primary. However, this is even less likely. Nothing in the petrology of the WCS suggests extensive alteration or reheating, such as might accompany regional remagnetization. Furthermore, nothing in the geological history of the area points to opportunities for remagnetization (e.g., extensive regional mineralization or deep burial). Finally, the sequence of polarity changes found in the WCS rocks argues that they were magnetized sequentially in a geomagnetic field undergoing polarity reversals. The hypothesis that a regional remagnetization event somehow produced the observed grouping of $N, R$, and $T$ directions is far less plausible.

Because we can dismiss the possibilities that the Western Cascade Series was deposited on a regionally extensive paleoslope to the east or that it was remagnetized after folding, we feel that we also can dismiss directions 7, Table 2, the WCS in situ mean, as a valid estimate of the direction of the ancient geomagnetic field. The fact that it is nearly identical to the North American Oligocene-early Miocene expected direction seems to be merely an uncomfortable coincidence.

of course, it is possible, al though not likely, that the WCS flows did accumulate with initial dip, but to the west rather than the east. This would be the case, for instance, if WCS exposures on the western side of the Cascade Range represent the western edge of mid-Tertiary volcanos now mostly buried beneath younger volcanic deposits along the crest of the range. If this were true, it would mean that our tilt corrections are too small. To act on this improbable scenario would require us to rotate all mean directions toward the east by some arbitrary angle (about $10^{\circ}$ ?) about a $N$ or $N W$ axis. This would have the effect of increasing paleomagnetic discordance, especially the amount of clockwise rotation.

We still need to explain the increase in scatter caused by applying local dips and strikes as tilt corrections. If, as we believe, the attitudes observed in the Western Cascade Series sequence in northern California are of postmagnetization origin, $k$ (an inverse measure of scatter) should increase, not decrease, upon "unfolding." Probably simple error is to blame. Faced with fragmentary outcrops of massive volcanic rocks (or volcanic rocks with flow structures, fissile parting, and other features that mimic bedding but may not be parallel to it), we apparently measured some local structure incorrectly, and these errors outweighed any decrease in scatter caused by correcting for real differences in tilt. Cases like this may not be uncommon where folded volcanic sequences are concerned.

\section{Tectonic Interpretation}

We conclude from the foregoing that our directions are reliable estimates of tectonic displacements and that they indicate that the southern end of the Cascade Range has rotated clockwise by about $15^{\circ}$ since the Western Cascade Series accumulated. Subdividing the data by age gives smaller data sets and thus mean directions that are less precise. Nevertheless, the lower half of the WCS seems to have been rotated more than the upper half. This implies that rotation was going on during WCS time. This is contrary 
TABLE 4. Directions of Remanent Magnetization for Seven "Most1y Oligocene" Units, Transformed to a Common Site Location $\left(44.3^{\circ} \mathrm{N}, 237.3^{\circ} \mathrm{E}\right)$

\begin{tabular}{|c|c|c|c|c|c|c|}
\hline & $D^{\prime}$ & $I^{\prime}$ & $\mathbf{N}$ & $\mathbf{r}$ & k & Reference \\
\hline WCI & $28.0^{\circ}$ & $62.6^{\circ}$ & 28 & 27.351 & 41.6 & Bates et al. [1981] \\
\hline OI & 38.7 & 56.0 & 14 & 13.349 & 20.0 & Beck and Plumley [1980] \\
\hline $\mathrm{CF}$ & 5.5 & 64.1 & 46 & 43.137 & 15.7 & $\begin{array}{l}\text { Gromme et al. (unpublished } \\
\text { manuscript, 1986) }\end{array}$ \\
\hline $\mathrm{YB}$ & 46.8 & 64.4 & 8 & 7.586 & 16.9 & Simpson and Cox [1977] \\
\hline WC2 & 25.1 & 70.7 & 14 & 13.521 & 27.1 & Magi11 and $\operatorname{Cox}[1980]$ \\
\hline WC3 & 22.2 & 66.5 & 10 & 9.317 & 13.2 & Magill and $\operatorname{Cox}$ [1980] \\
\hline WC4 & 5.0 & 59.8 & 53 & 49.388 & 14.4 & this paper \\
\hline
\end{tabular}

$D^{\prime}, I^{\prime}$ are declination and inclination transformed to a common site location $\left(44.3^{\circ} \mathrm{N}, 122.7^{\circ} \mathrm{W}\right)$. $\mathrm{N}, \mathrm{k}$ as in Table 1 ; $\mathrm{r}$ is length of vector sum, where each of $\mathrm{N}$ site-mean directions is assigned unit weight.

to the chronology for rotation proposed by Magil1 et a1. [1981] and Magill and Cox [1980]. It may be that the Magill model applies only to the Coast Range, or perhaps only farther north, beyond the tectonic influence of the Klamath crystalline block.

Most of the flattening values (IF) listed in Table 3 are smaller than their $95 \%$ confidence limits, and so in general it is possible to conclude that no north-south displacements of northern California (relative to stable North America) have taken place since WCS time. This is, of course, subject to the limitations of the paleomagnetic method, which for most individual studies cannot detect north-south displacements of less than about $750 \mathrm{~km}$. The one IF value in Table 3 that is significant at $95 \%$ confidence is calculation IV (mean direction for the lower WCS). Taken at face value, calculation IV suggests that the lower WCS rocks experienced northward transport of 700 or $800 \mathrm{~km}$ before the upper WCS flows were erupted. This is hard to accept on geological grounds, especially in light of paleomagnetic directions for WCS-equivalent rocks farther north (discussed below), which do not support northward transport. Elsewhere one of us [Beck, 1984] has argued for northward movement of the Oregon-Washington Coast Range, in part by strike-slip faulting after the range became part of North America. There is no particular reason why such northward transport could not extend to older Cascade volcanics adjacent to the Coast Range, but the bulk of evidence is against it. We suspect that the statistical "significance" of entry IV, Table 3, does not correctly imply genuine tectonic significance.

As mentioned in the introduction, although evidence for tectonic rotations within the Tertiary Coast Range and Cascades of Oregon, Washington, and northern California is convincing, neither the mechanisms of rotation nor the size of the coherent rotated blocks has been resolved to popular satisfaction. Obviously the two problems are interrelated; when the rotated blocks are mapped and their bounding structures understood, the mechanisms of rotation should be much easier to establish.

Paleomagnetism can contribute to the mapping of coherent rotated crustal blocks, but it is not well suited for the purpose. This is because of the statistical nature of paleomagnetic "judgments," which always turn critically on the question of error limits. Error limit calculations nearly always are made at a single confidence level (95\%), and they usually assume the Fisher [1953] distribution. Rarely, if ever, does the investigator demonstrate that his data actually conform to Fisher's distribution, however; most distributions do, but some do not. Also, the level of "significance" is arbitrary. For this reason it is extremely difficult to prove paleomagnetically that two areas have moved relative to one another; the evidence is completely convincing only if the amount of movement is very great. To an uncomfortable extent judgments about smal1 displacements are subjective.

Nevertheless, we attempted to use the available paleomagnetic data for Cascade and Coast Range rocks to say something about the scale of tectonic displacement since the midoligocene. The units studied are all mostly oligocene in age; we excluded units such as the Goble Volcanics that seem to be largely late Eocene, as well as several Miocene studies. There are seven studies; data and references are given in Table 4. Figure 3 shows sampling locations and rotation values. In the analysis that follows the assumption is made that all of these rock units are of the same age. This seems to be substantially correct, although no doubt differences in mean age of 5 or even $10 \mathrm{~m} . \mathrm{y}$. may exist. Given other probable sources of error and the tests that we intend to apply, this is not a fatal degree of imprecision.

Table 4 1ists "mean directions," with . appropriate statistics, for "mostly 0ligocene" rock units from the Pacific Northwest. However, these are not the mean directions actually observed at the sampling site; instead, Table 4 gives directions transformed to a common site longitude and latitude. The transformation involves the usually dipole-field assumption. Table 4 allows us to compare mean vectors of remanent magentization directly. We chose to work in "direction space" rather than "VGP space"! because as calculations given earlier demonstrate, directions are more sensitive than poles in detecting displacements. Also, VGP data were not available for all seven studies.

In Table 5 we attempt to show which pairs of 
TABLE 5. Values of the Statistic F for Pairs of "Mostly Oligocene" Units From the Pacific Northwest

\begin{tabular}{|c|c|c|c|c|c|c|c|}
\hline \multirow{2}{*}{ F Crit } & \multirow[b]{2}{*}{ WCI } & \multicolumn{3}{|c|}{$\bar{F}$} & \multirow[b]{2}{*}{ WC2 } & \multirow[b]{2}{*}{ WC3 } & \multirow[b]{2}{*}{ WC4 } \\
\hline & & OI & CF & YB & & & \\
\hline WCI & & 3.1 & 5.4 & 2.1 & 3.3 & 0.6 & 6.4 \\
\hline OI & 3.1 & & 8.4 & 1.2 & 5.9 & 2.4 & 8.0 \\
\hline $\mathrm{CF}$ & 3.1 & 3.1 & & 4.8 & 2.7 & 1.0 & 1.0 \\
\hline YB & 3.1 & 3.2 & 3.1 & & 1.8 & 1.0 & 5.7 \\
\hline WC2 & 3.1 & 3.2 & 3.1 & 3.2 & & 0.3 & 4.8 \\
\hline WC3 & 3.1 & 3.2 & 3.1 & 3.3 & 3.2 & & 1.8 \\
\hline WC4 & 3.1 & 3.1 & 3.0 & 3.1 & 3.1 & 3.1 & \\
\hline
\end{tabular}

Calculated (F) and critical ( $F_{\text {crit }}$ ) values of the statistic F (at $95 \%$ confidence), for the pairs of paleomagnetic studies indicated (see Figure 3 for identification of column and row headings). As an example of use: mean directions for WC3 and YB are not significantly different because $F(1.0)<F_{\text {crit }}(3.3)$. Note that CF may be more late Eocene than Oligocene in age.

directions are significantly different and which statistically identical, using the F test. We used the $F$ test because it seems to be a more sensitive way to detect tectonic displacments than the overlapping-confidence-circles technique. Table 5 gives critical values of $F$ ( $a$ function of $\mathrm{N}$ only) as well as actual $\mathrm{F}$ values (which depend on $\mathrm{N}$, dispersion, and the angle between the mean directions). To see whether two rocks units are "significantly different" (at $95 \%$ confidence), it is only necessary to compare F crit, from the lower half of Table 5, with $F$ from the top. If $F>F_{\text {fit }}$, the two rock units have mean directions that are significantly different.

Table 5 should be used with a little caution. First, because dispersion is a function of latitude, the values of $r$ used in the calculation of $F$ (derived from the in situ directions; Table 4) are very slightly incorrect. This affects estimates of $F$, but the effect is essentially negligible. Second, the F test is strictly valid only if dispersions in the data sets being compared are identical. Estimates (k) of Fisher's precision parameter (Table 4) for these studies are not strictly identical, although differences are not large. In preparing the discussion that follows we regarded only large values of $F$ ( $F$ > 4.5) as definite evidence of "significance," and we assume that two directions were irrefutably identical only if $F$ was very low $(\mathrm{F}>2.0)$.

We had hoped that Table 5 would allow us to map with some confidence regions that have undergone identical displacements, and therefore probably remained rigid during the displacement process. This does not appear to be the case. What Table 5 does say is the following (see also Table 6):

1. The entire area covered by the paleomagnetic studies shown in Figure 3 apparently has not acted as a rigid block since mid-0ligocene time. If it had, rotation values would be nearly identical, and all $\mathrm{F}$ values in Table 5 would be very low.

2. It is also not correct to visualize the area of Figure 3 as a collection of small crustal domains, each with its own completely independent displacement history. If this were the case, there would be no correlation whatever between geographic location of the sampling site and $R$ value, and neighboring sites would be no more likely to have low $\mathrm{F}$ values than sites that are far apart. However, the data show that there are such correlations, although they are not very impressive.

3. The entire area shows statistically significant amounts of clockwise rotation. Flattening values, on the other hand, are both positive and negative, and only one is significant at $95 \%$ confidence. These observations suggest that deformation of western Oregon, southwestern Washington, and northwestern California since the mid-0ligocene has been chiefly an in situ rotation, with little or no north-south displacement. (East-west displacement of course cannot be detected paleomagnetically.)

4. In a general way, rotation increases to the west or northwest. This is perhaps a bit easier to account for with a driving force on the western margin of the area (e.g., moving oceanic plates) than by a causal mechanism operating within the North American plate itself (e.g., extension in the Basin and Range province). However, there are other plausible scenarios [Wells and Coe, 1985; C.S. Gromme et al., unpublished manuscript, 1986]. Obviously, the issue remains unresolved.

Toward the end of a prolonged review of this manuscript we received information from an

TABLE 6. Rotation and Flattening Values for "Mostly 01igocene" Units From the Pacific Northwest

$\mathbf{R}$

IF

\begin{tabular}{|c|c|c|c|c|c|c|}
\hline WCI & 38.9 & \pm & $11.0^{\circ}$ & 1.9 & \pm & $5.2^{\circ}$ \\
\hline OI & 48.4 & \pm & 14.0 & 6.7 & \pm & 7.8 \\
\hline CF & 15.0 & \pm & 11.2 & -1.9 & \pm & 51.2 \\
\hline YB & 55.9 & \pm & 26.8 & -1.1 & \pm & 11.4 \\
\hline WC2 & 34.6 & \pm & 19.9 & -8.1 & \pm & 6.8 \\
\hline WC3 & 30.8 & \pm & 28.3 & -4.1 & \pm & 11.4 \\
\hline WC4 & 14.0 & \pm & 9.0 & 3.0 & \pm & 5.1 \\
\hline
\end{tabular}

Rotation ( $R$ ) and flattening (IF), with their respective $95 \%$ confidence limits. Units identified in Figure 3. 
anonymous source that suggests that the Clarno Formation (CF) is more nearly late Eocene than oligocene in age. Rather than restructure Tabies 4 and 5 and Figure 3 to omit CF, we have left it in, with the warning that the post-Eocene rotation of that unit may be even less than shown.

\section{Conclusions}

It seems certain that the southern tip of the Cascade Range in northern California has experienced clockwise rotation, relative to stable North America, of about $14^{\circ}$ since roughly mid-01igocene time. It also seems probable (but not certain) that much of this rotation took place during the late 01 igocene. All "mostly Oligocene" units so far studied in the Coast Range and Cascades show significant clockwise rotation. Statistical tests allow us to reject the hypothesis that they acted as a single rigid block, but neither do they appear to have rotated completely independently. A gradient in rotation values can be observed in the data; amounts of rotation increase to the west or northwest. If this is not an artifact of slight differences in age (which seems unlikely), it may indicate that the main driving force for rotation operated on the continental margin.

Acknowledgments. We thank D. Elston, B. Elwood, R. Reynolds, R. Simpson and an unknown Associate Editor for helpful reviews. G. Thompson first pointed M.E.B at the Western Cascade Series, over 25 years ago: his help and encouragement over the years is gratefully acknowledged. R. Schoonover was of great assigtance in the laboratory. National Science Foundation grant EAR 7924598 supported early work by Beck, Burmester, and Craig.

\section{References}

Bates, R. G., M. E. Beck, Jr., and R. F. Burmester, Tectonic rotations in the cascade Range of southern Washington, Geology, 9, 184$189,1981$.

Beck, M. E., Jr., Paleomagnetism of a thick Tertiary volcanic sequence in northern California, Rep. AFCRL 62-821, 45 pp., U.S. Air Force Cambridge Res. Lab., Cambridge, Mass., 1962.

Beck, M.E., Jr., Paleomagnetic record of platemargin tectonic processes along the western edge of North America, J. Geophys. Res., 85, $7115-7131,1980$.

Beck, M. E., Jr., Has the Washington-Oregon Coast Range moved northward?, Geology, 12, 737-740, 1984 .

Beck, M. E., Jr., and D. C. Engebretson, Paleomagnetism of small basalt exposures in the West Puget Sound area, Washington, and speculations on the accretionary origin of the Olympic Mountains, J. Geophys. Res., 87, 3755$3760,1982$.

Beck, M. E., Jr., and P. W. Plumley, Paleomagnetism of intrusive rocks in the Coast Range of Oregon: Micropolate rotations in middle Tertiary time, Geology, 8, 573-577, 1980.

Beck, M. E., Jr., R. F. Burmester, and R. Schoonover, Tertiary paleomagnetism of the
North Cascade Range, Washington, Geophys. Res. Lett., 9, 515-518, 1982 .

Beck, M. E., Jr., D. C. Engebretson, C. S. Gromme, E. M. Taylor, and J. W. Whitney, Paleomagnetism of the Middle Tertiary Clarno Formation, North-Central Oregon: Constraint on Models for Tectonic Rotation, EOS Trans. AGU, $59,1058,1978$.

Cox, A., Confidence limits for the precision parameter k, Geophys. J. R. Astron. Soc., 17 545-549, 1969 .

Craig, D. E., Paleomagnetism of a thick sequence of Middle Tertiary volcanic rocks from northern California: Tectonic rotation of the southern Cascades, M.s. thesis, 68 pp., West. Wash. Univ., Bellingham, 1981.

Craig, D. E., M. E. Beck, Jr., R. F. Burmester, and $R$. Schoonover, Modest clockwise rotation of the southern tip of the volcanic Cascades, northern California, EOS Trans. AGU, 62, 855, 1981 .

Demarest, H. H., Jr., Error analysis for the determination of tectonic rotation from paleomagnetic data, J. Geophys. Res., 88, 4321-4328, 1983.

Dieh1, J. F., M. E. Beck. Jr., S. Beske-Dieh1, D. Jacobson, and B. C. Hearn, Jr., Paleomagnetism of the Late Cretaceous-early Tertiary north central Montana alka1ic province, J. Geophys. Res., 88, 10,593-10,609, 1983.

Fisher, R. A., Dispersion on a sphere, Proc. R. Soc. London Ser., A, 217, 295-305, 1953.

Hammond, P. E., A tectonic model for the evolution of the Cascade Range, in Cenozoic Paleogeography of the Western United States edited by $\mathrm{J}$. Armentrout, M. Cole, and $\mathrm{H}$. Terbest, pp. 219-237, Society of Economic Paleontologists and Mineralogists, Los Angeles, Calif., 1979.

Hammond, P. E., Volcanic formations along the Klamath River near Copco Lake, Calif. Geol., 36, 99-109, 1983.

Magili, J., and A. Cox, Tectonic rotation of the Oregon Western Cascades, Spec. Pap. 10, 67 pp., Oreg. Dep. of Geol. Miner. Ind., Portland, 1980.

Magil1, J., A. Cox, and R. Duncan, Tillamook Volcanic Series: Further evidence for tectonic rotation of the Oregon Coast Range, J. Geophys. Res., 86, 2953-2970, 1981.

Magill, J., R. E. Wel $1 \mathrm{~s}$, R. W. Simpson, and A. Cox, Post $12 \mathrm{~m} . \mathrm{y}$. rotation of southwest Washington, J. Geophys. Res., 87, 3761-3776, 1982.

Mankinen, E. A., and W. P. Irwin, Paleomagnetic study of some Cretaceous and Tertiary sedimentary rocks of the Klamath Mountains province, California, Geology, 10, 82-87, 1982.

McFadden, P. L., and D. L. Jones, The fold test in paleomagnetism, Geophys. J. R. Astron. Soc. , 67, 53-58, 1981 .

McWilliams, M., Confidence limits on net tectonic rotation, Geophys. Res. Lett., 12, 825-827, 1984.

Ness, G., S. Levi, and R. Couch, Marine magnetic anomaly time scales for the Cenozoic and Late Cretaceous: A precis, critique and synthesis, Rev. Geophys. 18, 753-770, 1980.

Sheriff, S. D., Paleomagnetic evidence for spatially distributed post-Miocene rotation of western Washington and Oregon, Tectonics, 3 , 397-408, 1984. 
Simpson, R. W., and A. Cox, Paleomagnetic evidence for tectonic rotation of the Oregon Coast Range, Geology, 5, 585-589, 1977.

Wells, R. E., and R. S. Coe, Paleomagnetism and geology of Eocene volcanic rocks of southwest Washington: Implications for mechanisms of tectonic rotation, J. Geophys. Res., 90, 1925$1947,1985$.

Williams, H., Geology of the Macdoel Quadrangle, California, Bul1., Calif. Div. Mines, 151, 78 pp., 1949.

M. E..Beck, Jr., and R. F. Burmester, Department of Geology, Western Washington
University, Bellingham, WA 98225.

D. E. Craig, Alaska Exploration Group, Mobil Oi1 Co., $7200 \mathrm{~N}$. Stemmons, No. 486, Dallas, TX 75235 .

C. S. Gromme and R. E. Wells, U. S. Geological Survey, 345 Middlefield Road, Menlo Park, CA 94025 .

(Received August 6, 1985; revised February 21, 1986 ; accepted March 25, 1986.) 